\title{
Pre-transplant biomarkers and prediction of post- transplant outcomes in kidney transplantation
}

\author{
Maurizio Salvadori ${ }^{1^{*}}$, Aris Tsalouchos ${ }^{2}$ \\ ${ }^{1}$ Renal Unit Careggi University Hospital, Viale Pieraccini, Florence, Italy \\ ${ }^{2}$ Division of Nephrology Careggi University Hospital Largo Brambilla, Florence, Italy
}

\section{A R T I C L E I N F O}

Article Type:

Review

\section{Article History:}

Received: 9 January 2017

Accepted: 20 March 2017

Published online: 5 April 2017

\section{Keywords:}

Kidney transplantation

Pre-transplant biomarkers

Organ appraisal

Delayed graft function

Acute rejection

Chronic allograft dysfunction

\begin{abstract}
A B S T R A C T
Different biomarkers have been recently described bringing interesting results regarding predictive outcomes in the field of kidney transplantation. In this setting, an evaluation for pre-transplant biomarkers especially in the era of expanded criteria donors (ECDs) and non-heart-beating donors (NHBDs) could help transplant physicians to make decisions on allocation or even on discharge of the allograft. Furthermore, identify pre-transplant biomarkers is useful for a risk stratification of delayed graft function (DGF), acute rejection (AR) episodes and chronic allograft dysfunction (CAD) after kidney transplantation (KT). In this review, we report recent findings on pre-transplant biomarkers from various biological samples from donors or recipients.
\end{abstract}

Implication for health policy/practice/research/medical education:

New findings in "omics" and genomics allowed us to find out new robust biomarkers that may allow a diagnosis avoiding invasive and dangerous procedures. This could be of particular importance if applied on transplant clinical practice. In kidney transplantation several pre-transplant biomarkers revealed useful either for a better renal allocation and as predictive of future outcomes as delayed graft function, rejections and long term outcome.

Please cite this paper as: Salvadori M, Tsalouchos A. Pre-transplant biomarkers and prediction of post-transplant outcomes in kidney transplantation. J Renal Inj Prev. 2017;6(3):222-230. DOI: 10.15171/jrip.2017.42.

\section{Introduction}

Kidney transplantation (KT) appears to be the best replacement therapy of renal function for patients with end-stage renal disease (ESRD) as ameliorates significantly the quality of daily life, reduces mortality and lowers medical expense (1-3). The continuous increase of patients in ESRD, without a comparable availability of organs from cadaveric donors, has considerably extended the time in the waiting lists for KT (4). In attempt to increase the availability of organs from deceased donors, KT from expanded criteria donors (ECDs) and nonheart-beating donors (NHBDs) it turns out to be widely practiced.

Comparing the risk of graft loss, patients who received KT from ECDs have a 1.7-fold higher risk of graft loss compared transplant patients from standard criteria donors (SCDs) (5). Nevertheless, they appear to have better survival rates than patients who continue dialysis treatment (6). Furthermore, a kidney from a NHBD it turns out to have an extended period of cold ischemia, which could cause an irreversible damage with negative effects in terms of graft survival in middle and long distance from the time of transplantation. Therefore, while these kidneys help to counter the increasing demand for transplants, it is important for nephrologists and transplant surgeons to have the right tools in order to assess the quality of the graft, minimize the risk to transplant organs of poor quality, or discard vital organs. Current methods for evaluating the quality of kidneys for transplantation as donor age, creatinine levels or kidney 
biopsy, have shown limited precision in predicting early and long-term allograft outcomes (7).

The study of transplantation biology and biomarker research, is an important opportunity

in this context. Recent advances of proteomic and genomic analysis, in various fields of medicine, have inspired several researchers to conduct similar studies in the field of transplantation. They coined a new word for this field of study, calling it "Transplantomics" (8). In this review we report recent findings on pre transplant biomarkers from various biological samples from donors or recipients, their contribution in the assessment of graft, and their predictive value on early and long term outcomes after KT.

\section{Materials and Methods}

For this review, we used a variety of sources by searching through Web of Science, PubMed, EMBASE, Scopus and directory of open access journals (DOAJ). The search was performed using combinations of the following key words and or their equivalents such as; kidney transplantation, pre-transplant biomarkers, organ appraisal, delayed graft function, acute rejection, and chronic allograft dysfunction.

\section{Tissue biomarkers}

Nowadays, perform zero-time biopsy in KT is a widespread practice that influences decisions regarding graft allocation and kidney discard $(7,9)$. However, given the absence of valid associations between donor biopsy findings and post- transplant outcomes, the predictive value of zero-time biopsy is uncertain and its routine use to determine whether or not to transplant a kidney should be re-examined (10). Many researchers have attempted to overcome this obstacle by searching for intrarenal molecular expression as more suitable biomarker for post-transplant outcome. Primarily the researchers aim attention on the evaluation of certain molecules in the donor organ, which have been described to be cardinal indicators of ischemia-reperfusion injury (IRI). Among these, have been investigated adhesion molecules, heat shock proteins, apoptosis regulatory genes and components of the complement system.

In this setting, Schwarz et al (11) suggested that tubular epithelial cell adhesion molecule expression is not a predictor of acute rejection (AR) but could predict posttransplant delayed graft function (DGF) due to ischemia, as a significantly less expression of intercellular adhesion molecule 1 (ICAM-1) on tubular epithelial cells was seen in deceased donor kidneys that consequently had primary function against those with DGF. The same group of researchers (12) showed that, failure of up regulation of the anti-apoptotic genes B-cell lymphoma 2 (Bcl-2) and $\mathrm{B}$ cell lymphoma extra-large $(\mathrm{Bcl}-\mathrm{Xl})$ in cadaveric kidneys leads to DGF and to a higher incidence of tubular epithelial cells apoptosis, whereas cadaveric kidneys with primary function and living donor kidneys were vital enough to compensate ischemia by up regulation of the survival factors Bcl-2 and Bcl-Xl. Subsequently, Nijboer et al (13), showed that higher ICAM-1 as well as vascular cell adhesion molecule 1 (VCAM-1) staining in the kidney, although not augmented in the deceased donor kidneys in comparison with the living organ donor controls, have been associated with greater serum creatinine levels and inferior creatinine clearance at 1 and 3 years. Conversely, Heme oxygenase-1 (HO-1), a protective heat shock protein, documented to have a protective action, but exclusively in kidneys from living donors.

The hypothesis that brain death activate a stress-related reaction against which high levels of protective heat shock proteins, produced in the future graft, are able to counterbalance entirely this stress reaction have been opposed by Mueller et al (14) as a low Heat shock $70 \mathrm{kDa}$ protein 1 (HSP-72) expression in pre-transplant donor kidney biopsies failed to predict DGF or AR.

Recently, Kaminska et al (15) investigated the pretransplant histological expression of 29 genes involved in immune activation and cell migration, tissue injury and apoptosis. Lipocalin-2 (LCN2) or neutrophil gelatinaseassociated lipocalin (NGAL) displayed preminent expression in deceased donor kidneys biopsies and positively interconnected with DGF and/or AR episodes in the first 6 months after transplantation. Additionally, gene expression of hepatitis A virus cellular receptor 1 (HAVCR1) formerly known as kidney injury molecule 1 (KIM-1), associated positively with serum creatinine concentrations at six months post transplantation but, as documented in another study (16), did not predict DGF. The predictive value of the expression of complement components in preimplantation biopsies was as well investigated. Damman et al (17) acquired kidney biopsies from brain-dead donors and human living donors at the time of donation, after cold preservation, and after reperfusion of the graft. In brain-dead donors, C3 and fibrinogen deposition was increased at donation in comparison to living donors with no further deposition after cold ischemia or reperfusion. The authors documented that the expression of $\mathrm{C} 3$ after reperfusion was associated independently with decreased short-term function after transplantation in grafts from brain-dead donors. In untargeted microarray gene expression analyses, Hauser et al (18) illustrated differential expression of 48 genes associated with DGF in preimplantation biopsies of cadaveric donor kidneys. Beside complement genes that were decidedly up regulated into biopsies of DGF kidneys, many other genes correlated to metabolic, immune and cell communication pathways were up regulated in DGF kidneys. Part of this signature was confirmed afterward by the same authors in micro dissected zero-time biopsies (19). To check out the relationship with longer-term outcome, they have correlated microarray gene expression data in zero-time biopsies with glomerular filtration rate (GFR) at a distance of 12 months after transplantation. In this analysis, donor kidneys from recipients with impaired allograft function documented an up regulation of genes principally associated with oxidative stress response, functional classes of immunity, signal transduction and 
various complement genes. Analogously, was delineated an important gene expression disparities among living and deceased donor kidneys in pediatric kidney recipients (20). In this further extensive data-driven pathway analysis in preimplantation biopsies, repeatedly complement genes were decidedly enhanced, and in association with reduced primary graft function and also with graft function up to 3 years after transplantation. Beside complement gene expression, diverse pathways were decidedly enhanced in deceased donor kidneys, although to a minor measure. Recently in a large transcriptomic analysis was proved the enhancement of hypoxia, complement cascade and coagulation pathway in deceased versus living donor kidneys. Essentially, these expression dissimilarities were recognized by the time of procurement (before cold ischemia) in brain-death donor kidneys, and after first warm ischemia in deceased donor kidneys (21).

In addition, in targeted studies (22-24), mRNA levels of cyclin-dependent kinase inhibitor 2A (CDKN2A) in pretransplant kidney biopsies, one of the markers of cellular senescence, was documented as the most solid posttransplant predictor of serum creatinine at 6 months and one year in confront with clinical factors as age of donor and cold ischemic time. In addition, CDKN2A was also a solid predictor of DGF (24). In confirmation of this last finding, McGuinness et al (25) documented that the incidence of DGF was correlated with elevated CDKN2A expression and declined expression of hsa-miR-217 and hsa-miR-125b, two miRNAs (microRNAs) implicated in cellular damage responses as mediators of CDKN2 loci transcript expression. Analysis of these miRNA expression levels revealed their capacity to predict DGF in $83 \%$ of cases, with an overall specificity of $91 \%$ and sensitivity of 61\%. A direct comparison between the clinical method most commonly used to determine allograft suitability in the United Kingdom, the UK Kidney Donor Risk Index (UKKDRI) (26) and this microRNA model, called "the Glasgow Renal Performance Scoring System” (GRPSS), indicated that the GRPSS was better to predict DGF occurrence.

\section{Urine biomarkers}

Experimental and clinical models documented that, urinary biomarkers such as uNGAL, uKIM-1, uIL-18 and urinary L-type fatty acid-binding protein (uL-FABP) are specific markers of acute kidney injury (AKI) and/or IRI $(27,28)$. Different urinary biomarkers from recipients are also reported to predict primary non function (29-33). However, estimate recipient urinary biomarkers are not useful to make decisions regarding the acceptance and the subsequent allocation of cadaveric kidneys. In contrast, considering the current restrictions to allograft quality appraisal, donor urinary biomarker analysis could serve as a valuable assessment tool to decide on allograft selection and in addition make decisions on early perioperative recipient management.

Hollmen et al (34) examined the predictive value of uNGAL levels in deceased donors for the first time. None of the donors had clinically established AKI previous to death. In donors with high uNGAL, graft survival was lower after 1 year. Donor uNGAL was an independent risk factor for prolonged DGF ( $\geq 14$ days) in the multivariate analysis. However, failed to predict DGF in the receiver operating characteristic (ROC) analysis.

Reese et al (35) also documented the association of donor uNGAL with consequent DGF, but with lower incidence in comparison to the findings of Hollmen et al (34). Furthermore, both UNGAL and uL-FABP were in association with a lower estimated GFR (eGFR) at sixmonths, but only in recipients in absence of DGF. Based on these data, the authors concluding that donor urine injury biomarkers procure exiguous value to predict DGF and early allograft function after transplantation (35). Koo et al (36) reconsidered these data with their findings. They investigated the predictive value of donor UNGAL, uKIM-1 and uL-FABP for reduced graft function (RGF), defined as delayed or slow graft function, and graft function one year after transplantation. Donor uNGAL and $\mathrm{UL}$-FABP were associated with RGF. In addition the authors based on donor serum creatinine levels, uNGAL and uL-FABP, produced a scoring method to predict RGF. RGF prediction score showed a statistically superior diagnostic performance in comparison with the DGF calculator and the kidney donor profile index (KDPI). Levels of donor uL-FABP were also prognostic of allograft function after 1 year.

Recently, Puthumana et al (37) investigated the repair phase protein chitinase-3-like protein 1 (CHI3L1), also known as YKL-40, as new donor urinary biomarker. Increased donor urinary YKL-40 concentration showed to be in association with reduced risk of DGF. Furthermore, in the event of DGF, elevated donor urinary YKL-40 concentration was in association with higher 6-month eGFR. These findings indicate that YKL-40 is produced after tubular injury and is associated independently with recovery from DGF.

In smaller studies other possible donor urinary biomarkers have been investigated; Sárváry et al (38) showed that urine glutathione S-transferases (GST) was significantly related with the recovery of allograft function as defined by a comparison with the tubular enzymuria of GST in healthy controls. Shoskes et al (39) documented that a marker of oxidative function termed Trolox equivalent antioxidant capacity (TEAC), was associated with decreased urine concentration in donors from kidneys that were finally discarded or developed DGF in comparison with donor urine from kidneys that were transplanted and had primary function.

\section{Perfusate biomarkers}

Hypothermic machine perfusion (HMP) is used with the intention to limit the occurrence of DGF and ameliorate allograft function in comparison with static cold storage (40-42). Through the continuous perfusion of the kidney with a cold preservation solution, is able to remove toxic metabolites, decrease lactic acid production and provide 
nutrients from the kidney. In the United States by 2008, half of kidneys which underwent transplant from ECDs and $70 \%$ of NHBDs were machine perfused (43). The effects of persisting ischemia on the kidney in HMP, can be measured through the use of real-time pump parameter that consist in perfusion flow, perfusion pressure, and renal resistance. Many transplant centres actually estimate the quality of the kidney using these parameters $(44,45)$ even if the predictive value and the applicability of these physical measurements currently is questionable and must be established and validated by more extensive studies (46). In this context, the evaluation of non-invasive kidney injury biomarkers from perfusate solution could add a greater predictive value to kidney viability and allograft outcomes as concede assessment at multiple time points during preservation. Moers et al (47) have investigated for the first time six important perfusate biomarkers that have been supported in different studies and are already in use by various transplant centres (48-52). These biomarkers are; lactate dehydrogenase (LDH), aspartate aminotransferase (ASAT), total glutathione-S-transferase (GST), alanine-aminopeptidase (Ala-AP), N-acetyl- $\beta$-Dglucosaminidase (NAG), and heart type fatty acid binding protein (H-FABP). The researchers concluded that totalGST, NAG, and H-FABP were independent predictors of DGF but not of primary non-function (PNF) and graft survival. LDH, ASAT, and Ala-AP had no an independent predictive value for any of the endpoints. This study showed for the first time that kidney evaluation due measurements of perfusate biomarkers should not lead to discard of the organ.

Nagelschmidt et al (53) documented that in kidneys which developed DGF, the levels of total GST, a-GST and lipid peroxidation products (LPOP) at the end of HMP were higher. However, after multivariate analyses only LPOP correlated with DGF and none of the investigated biomarkers were in correlation with later outcomes.

In a prospective multicenter study which investigated the associations of alpha and pi iso-enzymes of GST with consequent DGF, Hall et al (54) showed that at the end of machine perfusion only pi-GST was independently associated with DGF.

In another study Snoeijs et al (55) discovered alpha1antritrypsin as a new perfusate biomarker that was up regulated in kidneys with DGF.

Hoogland et al (56), in one of the most important studies of the last years, evaluated in NHBDs, the predictive value of different perfusate biomarkers: GST, LDH, H-FABP and redox-active iron. Additionally, new potential perfusate biomarkers IL-18 and NGAL were measured. The predictive value of individual biomarkers for PNF was poor. Only redox-active iron and IL-18 improved to "fair" after counting clinically significant confounders in a multivariate analysis. LDH and IL-18 concentrations were correlated with DGF but none of the biomarkers analysed in this study was correlated with 1-year graft survival. The researchers concluded that the diagnostic relevance of the perfusate biomarkers to predict viability of kidneys from
NHBDs fluctuate from "poor" to "fair". Consequently, kidneys from NHBDs should not be discarded because of high concentration of a perfusate biomarker.

Similar conclusions were reached by Parikh et al (57) in the largest prospective multicenter cohort study, which investigated associations among perfusate biomarkers (NGAL, KIM-1, IL-18, L-FABP ) and pump parameters (resistance and flow) with DGF and allograft eGFR at six months.

Recently Guy et al (58) effectuated one-dimensional proton-nuclear magnetic resonance spectroscopy on 45-min and 4-h perfusate samples from 26 kidneys to demonstrate that 28 different metabolites varied in concentration during HMP, while specific metabolites (leucine, inosine, gluconate, and glucose) predicted DGF. miR-21, a novel biomarker described in AKI (59), was also investigated by Khalid et al (60) in the first study that evaluated the miRNA expression in HMP samples. miR-21 correlated with eGFR at 6 and 12 months posttransplantation, suggesting its use as a sentinel for early outcome following kidney transplant.

\section{Serum biomarkers}

Non-invasive pre-transplant serum biomarkers predictive of the recipient immune status might be a useful tool to prevent severe early AR episodes, as well as to identify patients with an increased risk of allograft failure.

One of the most well investigated pre-transplant serum biomarkers is the soluble form of CD30 (sCD30). CD30 is a $120-\mathrm{kDa}$ transmembrane glycoprotein and a member of the tumor necrosis factor receptor superfamily. Is preferentially expressed on human $\mathrm{CD} 4+$ and CD8+ T cells that secrete Th2-type cytokines (61) and the soluble form is released into the bloodstream after activation of CD30+ T cells (62). ESRD is correlated with various alterations of the immune system, including insufficient generation of Th2-type responses and regularly Th1-type cytokine-mediated chronic inflammation (63).

Increased serum sCD30 reflects the small portion of patients who are able to produce high amounts of the Th2type cytokine IL-10 which counterbalance this immune defect but could generate a potent alloimmune response against the allograft after KT. This has been supported by Weimer et al (64) in patients with high pre-transplantation IL-10-dominated Th2-type immune response and poor kidney graft outcome. The same group of researchers $(65,66)$ evaluated directly sCD30 that turned out to be an excellent predictor of kidney graft outcome as associated with graft rejection and significantly lower graft survival. Furthermore, sCD30 allowed the identification of highrisk recipients not only in patients with preformed antiHLA antibodies but also in non-sensitized patients without anti-HLA reactivity. Several other studies have been published and highlighted the relevance of pretransplantation serum concentration of $\mathrm{SCD} 30$ to predict AR episodes and allograft failure (67-71). However, some studies have found that pre-transplantation SCD30 levels are not different between patients with and without AR 
(72-80). Recently, a meta-analysis (81) documented that the accuracy of pre-transplantation SCD30 to predict post transplantation AR episodes was poor, suggesting the need of a further large prospective study.

Furthermore, other studies $(82,83)$ investigated whether pre-transplant serum determination of chemokine cxc motif ligand 10 (CXCL10), an interferon induced chemokine, whose expression is strongly associated with Th1-type immune responses, may predict the recipient's risk of graft rejection and transplant failure. These studies documented that patients with increased serum CXCL10 levels have a higher incidence of transplant failure, especially in the early post-transplant period and are more prone to AR episodes and a subsequent CAD. Afterward, a multicenter study obtained similar results with chemokine cxc motif ligand 9 (CXCL9) which, likewise CXCL10 is a ligand of chemokine cxc motif receptor 3 (CXCR3) (84). These findings suggest that CXCR3 ligands playing a pivotal role in the initiation and amplification of host alloresponses, in the development of AR and also in the pathogenesis of CAD, which finally leads to graft loss. Many other studies evaluated whether pre-transplant levels of different cytokines are associated with early post-transplant outcomes in recipients. Increased pretransplant plasma levels for soluble IL-6 receptor (sIL6R) (85) and low soluble gp130, another member of the IL-6 cytokine subfamily which functions as a transducer chain shared by many cytokines including IL6, shown to be associated with DGF (86).

In addition high pre-transplant levels of soluble IL-2 receptor (sIL-2R) (87), IL-2 (88), IL-6 (89), IL-12 (90), IL-10 (90) and INF- $\gamma(88,91)$ documented to predict AR episodes.

Using systematic application of INF- $\gamma$ enzyme linked immunospot (ELISPOT) assay, different studies documented that the pre-transplant frequency of donor specific INF- $\gamma$-producing cells correlates with AR among recipients of cadaveric kidney allograft (92-95)

These results were also confirmed in a population of living-donor kidney transplant recipients (96). Conversely, the recent Clinical Trial in Organ Transplantation (CTOT-01) multicenter study showed that pre-transplant IFN- $\gamma$ ELISPOT positivity did not correlates with the occurrence of AR. This study documented pre-transplant IFN- $\gamma$ ELISPOT positivity and lower post-transplant eGFR in patients who did not receive anti-thymocyte globulin (ATG) induction (97). These findings suggest that are needed controlled studies to test the hypothesis that in transplant candidates with high frequencies of donor-reactive memory $\mathrm{T}$ cells, the induction with ATG is preferential.

Recently, Nguyen el al (98) documented that recipient peripheral blood Treg suppressive function is a potential independent pre-transplantation predictor of DGF and slow graft function (SGF). The same authors (99) confirmed these findings using a simpler and alternative way to measure pre-transplant Treg cell function and predict DGF. In this study tumor necrosis factor receptor
2 (TNFR2) expressed on circulating Treg cells served as a surrogate phenotypic surface marker of pre-transplant Treg cell-suppressive function in patients awaiting a KT. Measuring pre-transplant circulating CD4+CD127lo/TNFR2+ Treg cells could therefore allow identification of recipients at risk for DGF before transplantation, and consequently guide organ allocation and DGF-targeted immunotherapy.

\section{Conclusion}

In summary, there are many potential pre-transplant biomarkers identified but until now none of them have been successful validated for routine clinical practice, as biomarkers with ideal specificity and sensitivity are difficult to be found. A potential solution is to use the combinatorial power of different biomarkers, each of which alone may not offer satisfaction in specificity or sensitivity. Furthermore, it is not enough to know what proportion of persons are reclassified by a biomarker into a different risk category; we also need to know whether a reclassification leads to health benefits. Predictive biomarkers suggest the population of patients who are likely to respond to a particular treatment. Before start using pre-transplant biomarkers in clinical practice is mandatory to identify more appropriate medical management strategies that will allow preventing an adverse outcome as DGF, AR episodes and CAD in order to have long-lasting function of these kidneys.

\section{Authors' contribution}

MS and AT equally designed the study, wrote the manuscript and revised the manuscript.

\section{Conflicts of interest}

The authors declare no conflicts of interest.

\section{Ethical considerations}

Ethical issues (including plagiarism, data fabrication, double publication) have been completely observed by the authors.

\section{Funding/Support}

No fund or support have been received for this study

\section{References}

1. Wolfe RA, Ashby VB, Milford EL, Ojo AO, Ettenger RE, Agodoa LY, et al. Comparison of mortality in all patients on dialysis, patients on dialysis awaiting transplantation, and recipients of a first cadaveric transplant. N Engl J Med. 1999;341:1725-30. doi: 10.1056/NEJM199912023412303.

2. Laupacis A, Keown P, Pus N, Krueger H, Ferguson B, Wong C, et al. A study of the quality of life and cost-utility of renal transplantation. Kidney Int. 1996;50:235-42. doi. org/10.1038/ki.1996.307.

3. Eggers P. Comparison of treatment costs between dialysis and transplantation. Semin Nephrol. 1992;12:284-9.

4. Cooper L. USRDS. 2001 Annual Data Report. Nephrol News Issues. 2001;15:31.

5. Port FK, Bragg-Gresham JL, Metzger RA, Dykstra DM, 
Gillespie BW, Young EW et al. Donor characteristics associated with reduced graft survival: an approach to expanding the pool of kidney donors. Transplantation. 2002;74:1281-6. doi: 10.1097/01.TP.0000034060.18738.0B.

6. Ojo AO, Hanson JA, Meier-Kriesche H, Okechukwu CN, Wolfe RA, Leichtman AB, et al. Survival in recipients of marginal cadaveric donor kidneys compared with other recipients and wait-listed transplant candidates. J Am Soc Nephrol. 2001;12:589-97.

7. Jochmans I, Pirenne J. Graft quality assessment in kidney transplantation: not an exact science yet! Curr Opin Organ Transplant. 2011;16:174-9. doi:10.1097/ MOT.0b013e3283446b31.

8. Sarwal MM, Benjamin J, Butte AJ, Davis MM, Wood K, Chapman J. Transplantomics and biomarkers in organ transplantation: a report from the first international conference. Transplantation. 2011;91:379-82. doi: 10.1097/ TP.0b013e3182105fb8.

9. Mueller TF, Solez K, Mas V. Assessment of kidney organ quality and prediction of outcome at time of transplantation. Semin Immunopathol. 2011;33:185-99. doi: 10.1007/ s00281-011-0248-x.

10. Wang CJ, Wetmore JB, Crary GS, Kasiske BL. The donor kidney biopsy and its implications in predicting graft outcomes: a systematic review. Am J Transplant. 2015;15:1903-14. doi: 10.1111/ajt.13213.

11. Schwarz C, Regele H, Steininger R, Hansmann C, Mayer $\mathrm{G}$, Oberbauer R. The contribution of adhesion molecule expression in donor kidney biopsies to early allograft dysfunction. Transplantation. 2001;71:1666-70.

12. Schwarz C, Hauser P, Steininger R, Regele H, Heinze G, Mayer G, et al. Failure of BCL-2 up-regulation in proximal tubular epithelial cells of donor kidney biopsy specimens is associated with apoptosis and delayed graft function. Lab Invest. 2002;82:941-8.

13. Nijboer WN, Schuurs TA, van der Hoeven JA, Fekken S, Wiersema-Buist J, Leuvenink HG, et al. Effect of brain death on gene expression and tissue activation in human donor kidneys. Transplantation. 2004;78:978-86. doi: 10.1097/01. TP.0000135565.49535.60.

14. Mueller T, Regele H, Posch M, Marszalek M, Schwarz C, Pichlhoefer B, et al. HSP-72 expression in pre-transplant donor kidney biopsies and post-transplant outcome. Transplantation. 2004;78:292-5.

15. Kamińska D, Kościelska-Kasprzak K, Drulis-Fajdasz D, Hałoń A, Polak W, Chudoba P, et al. Kidney ischemic injury genes expressed after donor brain death are predictive for the outcome of kidney transplantation. Transplant Proc. 2011;43:2891-4. doi: 10.1016/j.transproceed.2011.08.062

16. Schröppel B, Krüger B, Walsh L, Yeung M, Harris S, Garrison K, et al. Tubular expression of KIM-1 does not predict delayed function after transplantation. J Am Soc Nephrol. 2010;21:536-42. doi: 10.1681/ASN.2009040390.

17. Damman J, Nijboer WN, Schuurs TA, Leuvenink HG, Morariu AM, Tullius SG, et al. Local renal complement C3 induction by donor brain death is associated with reduced renal allograft function after transplantation. Nephrol Dial Transplant. 2011;26:2345-54. doi: 10.1093/ndt/gfq717.

18. Hauser P, Schwarz C, Mitterbauer C, Regele HM, Mühlbacher F, Mayer G, et al. Genome-wide geneexpression patterns of donor kidney biopsies distinguish primary allograft function. Lab Invest. 2004;84:353-61. doi:10.1038/labinvest.3700037.
19. Kainz A, Mitterbauer C, Hauser P, Schwarz C, Regele $\mathrm{HM}$, Berlakovich G, et al. Alterations in gene expression in cadaveric vs. live donor kidneys suggest impaired tubular counterbalance of oxidative stress at implantation. Am J Transplant. 2004;4:1595-604. doi: 10.1111/j.16006143.2004.00554.x.

20. Naesens M, Li L, Ying L, Sansanwal P, Sigdel TK, Hsieh SC, et al. Expression of complement components differs between kidney allografts from living and deceased donors. J Am Soc Nephrol. 2009;20:1839-51. doi: 10.1681/ ASN.2008111145.

21. Damman J, Bloks VW, Daha MR, van der Most PJ, Sanjabi $\mathrm{B}$, van der Vlies $\mathrm{P}$, et al. Hypoxia and complement-andcoagulation pathways in the deceased organ donor as the major target for intervention to improve renal allograft outcome. Transplantation. 2015;99:1293-300. doi: 10.1097/ TP.0000000000000500.

22. Koppelstaetter C, Schratzberger G, Perco P, Hofer J, Mark W, Ollinger R, et al. Markers of cellular senescence in zero hour biopsies predict outcome in renal transplantation. Aging Cell. 2008;7:491-7. doi:10.1111/j.1474-9726.2008.00398.x.

23. McGlynn LM, Stevenson K, Lamb K, Zino S, Brown M, Prina A, et al. Cellular senescence in pretransplant renal biopsies predicts postoperative organ function. Aging Cell. 2009;8:45-51. doi:10.1111/j.1474-9726.2008.00447.x

24. Gingell-Littlejohn M, McGuinness D, McGlynn LM, Kingsmore D, Stevenson KS, Koppelstaetter C, et al. Pretransplant CDKN2A expression in kidney biopsies predicts renal function and is a future component of donor scoring criteria. PLoS One. 2013;8:e68133. doi:10.1371/journal. pone. 0068133 .

25. McGuinness D, Leierer J, Shapter O, Mohammed S, Gingell-Littlejohn M, Kingsmore DB, et al. Identification of molecular markers of delayed graft function based on the regulation of biological ageing. PLoS One. 2016;11: e0146378. doi: 10.1371/journal.pone.0146378.

26. Watson CJ, Johnson RJ, Birch R, Collett D, Bradley JA. A simplified donor risk index for predicting outcome after deceased donor kidney transplantation. Transplantation. 2012;93:314-8. doi: 10.1097/TP.0b013e31823f14d4.

27. Haase M, Bellomo R, Devarajan P, Schlattmann P, HaaseFielitz A. NGAL Meta analysis Investigator Group. Accuracy of neutrophil gelatinase-associated lipocalin (NGAL) in diagnosis and prognosis in acute kidney injury: a systematic review and meta-analysis. Am J Kidney Dis. 2009;54:1012-24. doi: 10.1053/j.ajkd.2009.07.020.

28. Siew ED, Ware LB, Ikizler TA. Biological markers of acute kidney injury. J Am Soc Nephrol. 2011;22:810-20. doi: 10.1681/ASN.2010080796

29. Fonseca I, Oliveira JC, Almeida M, Cruz M, Malho A, Martins LS et al. Neutrophil gelatinase-associated lipocalin in kidney transplantation is an early marker of graft dysfunction and is associated with one-year renal function. J Transplant. 2013;2013:650123. doi: 10.1155/2013/650123

30. Mishra J, Ma Q, Kelly C, Mitsnefes M, Mori K, Barasch J et al. Kidney NGAL is a novel early marker of acute injury following transplantation. Pediatr Nephrol. 2006;21:85663. doi:10.1007/s00467-006-0055-0

31. Sureshkumar KK, Marcus RJ. Urinary biomarkers as predictors of long-term allograft function after renal transplantation. Transplantation. 2010;90:688-9. doi: 10.1097/TP.0b013e3181 ebc0d6.

32. Pajek J, Škoberne A, Šosterič K, Adlešič B, Leskošek B, 
Bučar Pajek M, et al. Non-inferiority of creatinine excretion rate to urinary L-FABP and NGAL as predictors of early renal allograft function. BMC Nephrol. 2014;15:117. doi: 10.1186/1471-2369-15-117.

33. Malyszko J, Koc-Zorawska E, Malyszko JS, Mysliwiec M. Kidney injury molecule-1 correlates with kidney function in renal allograft recipients. Transplant Proc. 2010;42: 3957-9. doi: 10.1016/j.transproceed.2010.10.005.

34. Hollmen ME, Kyllönen LE, Inkinen KA, Lalla ML, Merenmies J, Salmela KT. Deceased donor neutrophil gelatinase-associated lipocalin and delayed graft function after kidney transplantation: a prospective study. Crit Care. 2011;15:R121. doi: 10.1186/cc10220.

35. Reese PP, Hall IE, Weng FL, Schröppel B, Doshi MD, Hasz $\mathrm{RD}$, et al. Associations between deceased-donor urine injury biomarkers and kidney transplant outcomes. J Am Soc Nephrol. 2016;27:1534-43. doi: 10.1681/ASN.2015040345.

36. Koo TY, Jeong JC, Lee Y, Ko KP, Lee KB, Lee S, et al. Pretransplant evaluation of donor urinary biomarkers can predict reduced graft function after deceased donor kidney transplantation. Medicine (Baltimore). 2016;95:e3076. doi: 10.1097/MD.0000000000003076

37. Puthumana J, Hall IE, Reese PP, Schröppel B, Weng FL, Thiessen-Philbrook $\mathrm{H}$, et al. YKL-40 associates with renal recovery in deceased donor kidney transplantation. J Am Soc Nephrol. 2017;28:661-670. doi: 10.1681/ ASN.2016010091.

38. Sárváry E, Nemes B, Járay J, Dinya E, Borka P, Varga $M$, et al. Prediction of early renal graft function by the measurement of donor urinary glutathione S-transferases. Transplantation. 2000;69:1397-402.

39. Shoskes DA, Webster R, Shahed A. Oxidant stress in cadaveric and living kidney donors as markers of renal injury: utility of total antioxidant capacity and isoprostane levels in urine. Transplant Proc. 2000;32:804-5. doi: 10.1016/S0041-1345(00)00991-X.

40. Cannon RM, Brock GN, Garrison RN, Smith JW, Marvin MR, Franklin GA. To pump or not to pump: a comparison of machine perfusion vs cold storage for deceased donor kidney transplantation. J Am Coll Surg. 2013;216:625-33. doi: 10.1016/j.jamcollsurg.2012.12.025

41. O'Callaghan JM, Morgan RD, Knight SR, Morris PJ. Systematic review and meta-analysis of hypothermic machine perfusion versus static cold storage of kidney allografts on transplant outcomes. Br J Surg. 2013;100: 9911001. doi: 10.1002/bjs.9169.

42. Gill J, Dong J, Eng M, Landsberg D, Gill JS. Pulsatile perfusion reduces the risk of delayed graft function in deceased donor kidney transplants, irrespective of donor type and cold ischemic time. Transplantation. 2014;97:66874. doi: 10.1097/01.TP.0000438637.29214.10.

43. Klein AS, Messersmith EE, Ratner LE, Kochik R, Baliga $\mathrm{PK}$, Ojo AO. Organ donation and utilization in the United States, 1999-2008. Am J Transplant. 2010;10:973-86. doi: 10.1111/j.1600-6143.2009.03008.x.

44. Kozaki K, Sakurai E, Kubota K, Iwamoto H, Hama K, Narumi Y, et al. Prediction of kidney nonfunction after transplantation with machine perfusion preservation. Transplant Proc. 2000;32:275-6. doi: 10.1016/S00411345(99)00955-0.

45. Talbot D, Shenton BK, Buckley PE, Gok MA. Experiences learned in the successful establishment of a nonheart beating donor program for renal transplantation. J Urol.
2004;171:359. doi: 10.1097/01.ju.0000086774.12582.0f.

46. van Smaalen TC, Hoogland ER, van Heurn LW. Machine perfusion viability testing. Curr Opin Organ Transplant. 2013;18:168-73. doi: 10.1097/MOT.0b013e32835e2a1b.

47. Moers C, Varnav OC, van Heurn E, Jochmans I, Kirste GR, Rahmel A, et al. The value of machine perfusion perfusate biomarkers for predicting kidney transplant outcome. Transplantation. 2010;90: 966-73. doi: 10.1097/ TP.0b013e3181f5c40c.

48. Daemen JW, Oomen AP, Janssen MA, van de Schoot L, van Kreel BK, Heineman E, et al. Glutathione S-transferase as predictor of functional outcome in transplantation of machine-preserved non-heart-beating donor kidneys. Transplantation. 1997;63:89-93.

49. Gok MA, Pelzers M, Glatz JF, Shenton BK, Buckley PE, Peaston R, et al. Do tissue damage biomarkers used to assess machine-perfused NHBD kidneys predict long-term renal function post-transplant? Clin Chim Acta. 2003;338: 33-43. doi: 10.1016/j.cccn.2003.07.023.

50. Gok MA, Pelsers M, Glatz JF, Shenton BK, Peaston R, Cornell C, et al. Use of two biomarkers of renal ischemia to assess machine-perfused non-heart-beating donor kidneys. Clin Chem. 2003;49:172-5. doi: 10.1373/49.1.172.

51. Murugan R, Venkataraman R, Wahed AS, Elder M, Hergenroeder G, Carter $\mathrm{M}$ et al; HIDonOR Study Investigators. Increased plasma interleukin-6 in donors is associated with lower recipient hospital-free survival after cadaveric organ transplantation. Crit Care Med. 2008;36:1810-6. doi: 10.1097/CCM.0b013e318174d89f.

52. Daemen JH, Heineman E, Kootstra G. Viability assessment of non-heart-beating donor kidneys during machine preservation. Transplant Proc. 1995;27:2906-7.

53. Nagelschmidt M, Minor T, Gallinat A, Moers C, Jochmans I, Pirenne J et al. Lipid peroxidation products in machine perfusion of older donor kidneys. J Surg Res. 2013;180: 337-42. doi: 10.1016/j.jss.2012.04.071.

54. Hall IE, Bhangoo RS, Reese PP, Doshi MD, Weng FL, Hong $\mathrm{K}$, et al. Glutathione S-transferase iso-enzymes in perfusate from pumped kidneys are associated with delayed graft function. Am J Transplant. 2014;14:886-96. doi: 10.1111/ ajt.12635.

55. Snoeijs MG, Pulinx B, van Dieijen-Visser MP, Buurman WA, van Heurn LW, Wodzig WK et al. Characterization of the perfusate proteome of human donor kidneys. Ann Clin Biochem. 2013;50:140-6. doi: 10.1258/acb.2012.011144.

56. Hoogland ER, de Vries EE, Christiaans MH, Winkens B, Snoeijs MG, van Heurn LW. The value of machine perfusion biomarker concentration in DCD kidney transplantations. Transplantation. 2013;95:603-10. doi: 10.1097/TP.0b013e31827908e6.

57. Parikh CR, Hall IE, Bhangoo RS, Ficek J, Abt PL, ThiessenPhilbrook $\mathrm{H}$ et al. Associations of perfusate biomarkers and pump parameters with delayed graft function and deceased donor kidney allograft function. Am J Transplant. 2016;16: 1526-39. doi: 10.1111/ajt.13655.

58. Guy AJ, Nath J, Cobbold M, Ludwig C, Tennant DA, Inston NG, et al. Metabolomic analysis of perfusate during hypothermic machine perfusion of human cadaveric kidneys. Transplantation. 2015;99:754-9. doi: 10.1097/ TP.0000000000000398.

59. Li YF, Jing Y, Hao J, Frankfort NC, Zhou X, Shen B, et al. MicroRNA-21 in the pathogenesis of acute kidney injury. Protein Cell. 2013;4:813-9. doi: 10.1007/s13238-013-3085-y 
60. Khalid U, Ablorsu E, Szabo L, Jenkins RH, Bowen T, Chavez $\mathrm{R}$, et al. MicroRNA-21 (miR-21) expression in hypothermic machine perfusate may be predictive of early outcomes in kidney transplantation. Clin Transplant. 2016;30:99-104. doi: $10.1111 /$ ctr.12679.

61. Del Prete G, De Carli M, Almerigogna F, Daniel CK, D’Elios MM, Zancuoghi G, et al. Preferential expression of CD30 by human CD4+ $\mathrm{T}$ cells producing Th2-type cytokines. FASEB J. 1995;9: 81-6.

62. Romagnani S, Del Prete G, Maggi E, Chilosi M, CaligarisCappio F, Pizzolo G. CD30 and type 2 T helper (Th2) responses. J Leukoc Biol. 1995;57:726-30.

63. Girndt M, Sester M, Sester U, Kaul H, Köhler $H$. Molecular aspects of T- and B-cell function in uremia. Kidney Int Suppl. 2001;78:S206-11. doi: 10.1046/j.15231755.2001.59780206.x.

64. Weimer R, Zipperle S, Daniel V, Carl S, Staehler G, Opelz G. Pretransplant CD4 helper function and interleukin 10 response predict risk of acute kidney graft rejection. Transplantation. 1996;62:1606-14.

65. Pelzl S, Opelz G, Wiesel M, Schnülle P, Schönemann C, Döhler B, et al. Soluble CD30 as a predictor of kidney graft outcome. Transplantation. 2002;73:3-6.

66. Süsal C, Pelzl S, Döhler B, Opelz G. Identification of highly responsive kidney transplant recipients using pretransplant soluble CD30. J Am Soc Nephrol. 2002;13:1650-6. doi: 10.1097/01.ASN.0000014256.75920.5B.

67. Rajakariar R, Jivanji N, Varagunam M, Rafiq M, Gupta A, Sheaff $M$, et al. High pre-transplant soluble CD30 levels are predictive of the grade of rejection. Am J Transplant. 2005;5:1922-5. doi: 10.1111/j.1600-6143.2005.00966.x.

68. Cinti P, Pretagostini R, Arpino A, Tamburro ML, Mengasini S, Lattanzi R, et al. Evaluation of pretransplant immunologic status in kidney-transplant recipients by panel reactive antibody and soluble CD30 determinations. Transplantation. 2005;79:1154-6. doi: 10.1097/01. TP.0000152660.56055.53.

69. Sengul S, Keven K, Gormez U, Kutlay S, Erturk S, Erbay B. Identification of patients at risk of acute rejection by pretransplantation and posttransplantation monitoring of soluble CD30 levels in kidney transplantation. Transplantation. 2006;81:1216-9. doi: 10.1097/01. tp.0000203324.49969.30.

70. Altermann W, Schlaf G, Rothhoff A, Seliger B. High variation of individual soluble serum $\mathrm{CD} 30$ levels of pretransplantation patients: $\mathrm{sCD} 30$ a feasible marker for prediction of kidney allograft rejection? Nephrol Dial Transplant. 2007;22:2795-9. doi: 10.1093/ndt/gfm397.

71. Shooshtarizadeh T, Mohammadali A, Ossareh S, Ataipour Y. Relation between pretransplant serum levels of soluble CD30 and acute rejection during the first 6 months after a kidney transplant. Exp Clin Transplant. 2013;11:229-33. doi: 10.6002/ect.2012.0113.

72. Ayed K, Abdallah TB, Bardi R, Abderrahim E, Kheder A. Plasma levels of soluble CD30 in kidney graft recipients as predictors of acute allograft rejection. Transplant Proc. 2006 Sep;38: 2300-2. doi: 10.1016/j.transproceed.2006.07.002

73. Nafar M, Farrokhi F, Vaezi M, Entezari AE, Pour-RezaGholi F, Firoozan A, et al. Pre-transplant and posttransplant soluble CD30 for prediction and diagnosis of acute kidney allograft rejection. Int Urol Nephrol. 2009;41: 687-93. doi: 10.1007/s11255-008-9505-X.

74. Azarpira N, Aghdaie MH, Malekpour Z. Soluble CD30 in renal transplant recipients: is it a good biomarker to predict rejection? Saudi J Kidney Dis Transpl. 2010;21:31-6.

75. Giannoli C, Bonnet MC, Perrat G, Houillon A, Reydet S, Pouteil-Noble C, et al. High pretransplantation soluble CD30 levels: impact in renal transplantation. Transplant Proc. 2007;39:2574-5. doi: 10.1016/j.transproceed.2007.08.013.

76. Kovač J, Arnol M, Vidan Jeras B, Bren AF, Kandus A. Pretransplant soluble CD30 serum concentration does not affect kidney graft outcomes 3 years after transplantation. Transplant Proc. 2010;42:4043-6. doi: 10.1016/j. transproceed.2010.09.050.

77. Kim MS, Kim HJ, Kim SI, Ahn HJ, Ju MK, Kim HJ, et al. Pretransplant soluble CD30 level has limited effect on acute rejection, but affects graft function in living donor kidney transplantation. Transplantation. 2006;82:1602-5. doi: 10.1097/01.tp.0000248779.17754.5e.

78. Spiridon C, Nikaein A, Lerman M, Hunt J, Dickerman R, Mack M. CD30, a marker to detect the high-risk kidney transplant recipients. Clin Transplant. 2008;22:765-9. doi: 10.1111/j.1399-0012.2008.00876.x.

79. Matinlauri IH, Kyllönen LE, Salmela KT, Helin H, Pelzl S, Süsal C. Serum sCD30 in monitoring of alloresponse in well HLA-matched cadaveric kidney transplantations. Transplantation. 2005;80:1809-12. doi: 10.1097/01. tp.0000188175.66835.c6

80. López-Hoyos M, San Segundo D, Benito MJ, FernándezFresnedo G, Ruiz JC, Rodrigo E, et al. Association between serum soluble CD30 and serum creatinine before and after renal transplantation. Transplant Proc. 2008;40:2903-5. doi: 10.1016/j.transproceed.2008.08.087.

81. Chen Y, Tai Q, Hong S, Kong Y, Shang Y, Liang W, et al. Pretransplantation soluble CD30 level as a predictor of acute rejection in kidney transplantation: a metaanalysis. Transplantation. 2012;94:911-8. doi: 10.1097/ TP.0b013e31826784ad

82. Rotondi M, Rosati A, Buonamano A, Lasagni L, Lazzeri E, Pradella F, et al. High pretransplant serum levels of CXCL10/ IP-10 are related to increased risk of renal allograft failure. Am J Transplant. 2004;4:1466-74. doi: 10.1111/j.16006143.2004.00525.x.

83. Lazzeri E, Rotondi M, Mazzinghi B, Lasagni L, Buonamano A, Rosati A, et al. High CXCL10 expression in rejected kidneys and predictive role of pretransplant serum CXCL10 for acute rejection and chronic allograft nephropathy. Transplantation. 2005;79:1215-20. doi: 10.1097/01. TP.0000160759.85080.2E.

84. Rotondi M, Netti GS, Lazzeri E, Stallone G, Bertoni E, Chiovato L et al. High pretransplant serum levels of CXCL9 are associated with increased risk of acute rejection and graft failure in kidney graft recipients. Transpl Int. 2010;23:46575. doi: 10.1111/j.1432-2277.2009.01006.x.

85. Sadeghi M, Daniel V, Naujokat C, Mehrabi A, Opelz G. Association of high pretransplant sIL-6R plasma levels with acute tubular necrosis in kidney graft recipients. Transplantation. 2006;81:1716-24. doi: 10.1097/01. tp.0000226076.04938.98.

86. Sadeghi M, Daniel V, Lahdou I, Döhler B, Naujokat C, Renner FC, et al. Association of pretransplant soluble glycoprotein 130 (sgp130) plasma levels and posttransplant acute tubular necrosis in renal transplant recipients. Transplantation. 2009;88:266-71. doi: 10.1097/TP.0b013e3181ac8d81.

87. Lee PH, Chung YC, Hu RH, Huang MT, Chao SH, Lee CJ, et al. Serum interleukin-2 and soluble interleukin-2 receptor 
in renal transplant recipients. J Formos Med Assoc. 1992 Sep;91: 844-8.

88. Lessan-Pezeshki M, Amirzargar A, Fathi A, Khatami MR, Einollahi B, Pourfarziani V, et al. Value of pretransplantation cytokine profiles for predicting acute rejection in renal transplant recipients. Transplant Proc. 2005;37:2982-4. doi: 10.1016/j.transproceed.2005.08.031.

89. Berber I, Yiğit B, Işitmangil G, Tellioğlu G, Ozgezer T, Gülle $S$, et al. Evaluation of pretransplant serum cytokine levels in renal transplant recipients. Transplant Proc. 2008;40:92-3. doi: 10.1016/j.transproceed.2007.11.048

90. Fitzgerald JT, Johnson JR, Perez RV. Pre-transplant elevations of interleukin-12 and interleukin-10 are associated with acute rejection after renal transplantation. Clin Transplant. 2004;18:434-9. doi: 10.1111/j.13990012.2004.00185.x.

91. Sadeghi M, Daniel V, Weimer R, Wiesel M, Hergesell O, Opelz G. Pre-transplant Th1 and post-transplant Th2 cytokine patterns are associated with early acute rejection in renal transplant recipients. Clin Transplant. 2003;17: 151-7.

92. Augustine JJ, Siu DS, Clemente MJ, Schulak JA, Heeger PS, Hricik DE. Pre-transplant IFN-gamma ELISPOTs are associated with post-transplant renal function in African American renal transplant recipients. Am J Transplant. 2005;5:1971-5. doi: 10.1111/j.1600-6143.2005.00958.x

93. Bendjelloul F, Desin TS, Shoker AS. Donor non-specific IFN-gamma production by primed alloreactive cells as a potential screening test to predict the alloimmune response. Transpl Immunol. 2004;12:167-76. doi: 10.1016/j. trim.2003.08.003

94. Heeger PS, Greenspan NS, Kuhlenschmidt S, Dejelo C, Hricik DE, Schulak JA, et al. Pretransplant frequency of donor-specific, IFN-gamma-producing lymphocytes is a manifestation of immunologic memory and correlates with the risk of posttransplant rejection episodes. J Immunol. 1999;163:2267-75.

95. Bellisola G, Tridente G, Nacchia F, Fior F, Boschiero L. Monitoring of cellular immunity by interferon-gamma enzyme-linked immunosorbent spot assay in kidney allograft recipients: preliminary results of a longitudinal study. Transplant Proc. 2006;38: 1014-7. doi: 10.1016/j. transproceed.2006.02.142

96. Kim SH, Oh EJ, Kim MJ, Park YJ, Han K, Yang HJ, et al. Pretransplant donor-specific interferon-gamma ELISPOT assay predicts acute rejection episodes in renal transplant recipients. Transplant Proc. 2007;39:3057-60. doi: 10.1016/j. transproceed.2007.06.080

97. Hricik DE, Augustine J, Nickerson P, Formica RN, Poggio $\mathrm{ED}$, Rush $\mathrm{D}$, et al; CTOT-01 consortium. Interferon Gamma ELISPOT Testing as a Risk-Stratifying Biomarker for Kidney Transplant Injury: Results From the CTOT-01 Multicenter Study. Am J Transplant. 2015;15: 3166-73. doi: 10.1111/ajt.13401

98. Nguyen MT, Fryml E, Sahakian SK, Liu S, Michel RP, Lipman ML, et al. Pretransplantation recipient regulatory $\mathrm{T}$ cell suppressive function predicts delayed and slow graft function after kidney transplantation. Transplantation. 2014;98:745-53. doi: 10.1097/TP.0000000000000219

99. Nguyen MT, Fryml E, Sahakian SK, Liu S, Cantarovich $\mathrm{M}$, Lipman $\mathrm{M}$, et al. Pretransplant recipient circulating $\mathrm{CD} 4+\mathrm{CD} 127 \mathrm{lo} /-$ tumor necrosis factor receptor $2+$ regulatory $\mathrm{T}$ cells: a surrogate of regulatory $\mathrm{T}$ cellsuppressive function and predictor of delayed and slow graft function after kidney transplantation. Transplantation. 2016;100:314-24. doi: 10.1097/TP.0000000000000942.

Copyright (C) 2017 The Author(s); Published by Nickan Research Institute. This is an open-access article distributed under the terms of the Creative Commons Attribution License (http://creativecommons.org/licenses/by/4.0), which permits unrestricted use, distribution, and reproduction in any medium, provided the original work is properly cited. 